toms of inflammation of the brain or its membranes. Should these symptoms arise, the pulse is the best index for treatment. On reference to Case IV, it will be seen that the patient was treated with stimulants from the first ; but it will also be seen that his pulse was weak, and after the first day never over sixty, until just before his decease, when it mounted rapidly. Should, however, the pulse increase in number and volume, as in Case II, small doses of calomel and counterirritation are the remedies; but it appears that these patients bear the administration of mercury less well than cases of the idiopathic form of this disease. The quantity, however, must be regulated by the state of the pulse.

\section{Griginal Commuxriations.}

\section{ENTOPTICS :}

OBSERVATIONS ON THE RELATIVELY GREATER FREQLENCY OF MYODESOPIA IN THE MYOPIC EYE.

By Jabez Hogq, Esq., Assistant-Surgeon to the Royal Westminster Ophthalmic Hospital, etc.

[Concluded from page $50 \%$.]

TrE pearly and watery spectra are invariably associated with the earliest symptoms in nearly all affections of the conjunctivæ. The student sitting late and long over his books or microscope; the astronomer at his telescope, after long hours of night watching; the barrister and lawyer; are all, sooner or later, warned to desist by various troublesome spectra which confuse and dim the sight. Another class of sufferers from muscæ volitantes are those whose occupations make increasing demands upon the organ of vision. Intently occupied, it may be, in a badly-lighted and ill-ventilated room, and in a bent and constrained position, for many consecutive hours. An example or two of this class will serve to show the kind of annoyance usually experienced by them.

A gentleman, constantly engaged as a draughtsman, suffered for some time from spectra, which increased to such an extent, that after two hours at most he could proceed no longer with his work. A complete blur or black blot settled down over certain portions of the drawing, chiefly taking the form represented in fig. 10 . If the day were cloudy, or the

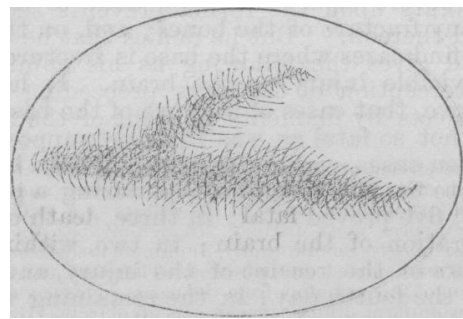

Fig. 10.

general health at all disturbed, they were much more troublesome; and always appeared to move in the horizontal plane. When walking the spectra took other forms; generally some six to ten feet in advance and above the line of vision, and looking like groups of pearly drops. Upon raising the head, they then had all the appearance of a cluster of stars or crystals, represented in fig. 11. Apparitions of the lacrymal fluids were nearly always visible, and espe-

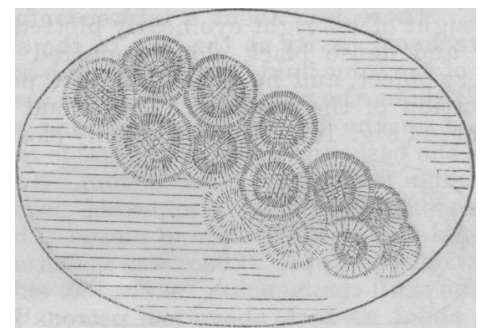

Fig. 11.

cially so after long fasting or fatigue; but much less troublesome when walking in a brilliant sunshine. At times, he thought rain was falling before him, each drop being surrounded by a bright halo of colours ; then, again, descending more slowly, gliding, as it were, before the pupil, as represented in fig. 12.

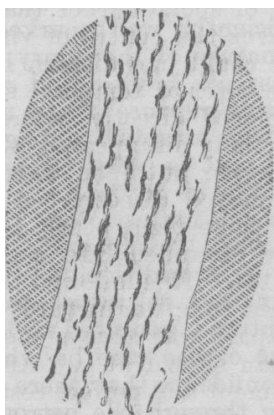

Fig. 12.

As this gentleman reciuired only the occasional use of concave glasses for distant objects, it may be assumed that the spectra most annoying to him were in a great measure due to rays of light falling upon the retina in a state of dissipation.

Another illustrative case was that of a law-writer, also myopic, who, after days and nights of great fatigue, being at the time employed in the preparation of Parliamentary papers, became the subject of most annoying pearly and watery spectra. These were at one time associated with the more alarming symptoms of paralysis of the retina ; insensible portions of which caused a partial obliteration of all objects. Letters and words were completely broken up, and occasionally quite blotted out; and when the head was thrown up, watery spectra fell over the sight like jets

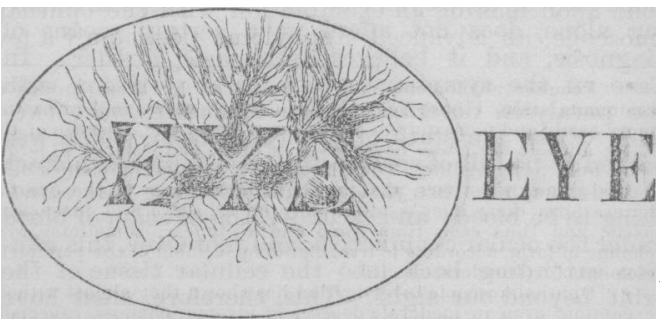

Fig. 18.

of spray from a fountain; or at other times resembling branches of trees covered with snow, as in in fig. 13. Compare this with the good bold Roman 
type near, and the defect will be at once understood.*

A tutor, myopic from childhood, after a long and anxious period, arose one morning from his bed to find the sight of his right eye nearly blotted out. A peculiar and dense black cloud appeared to hang over every object, and he could but just perceive a small portion of the window. This cloud is represented at B (Fig. 14). Upon suddenly closing both

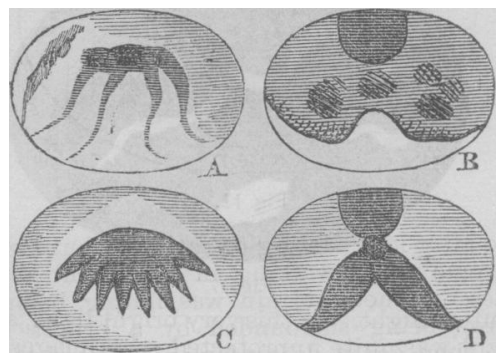

Fig. 14.

eyes, a number of spots darker than the cloud appeared to fall over the centre of vision. In a very strong light, he could just discern his hand, if held very near to the outer or temporal side of the head; but not so if placed directly before the eye. The black cloud partially disappeared when he assumed the upright position; but upon walking, a cloud not quite so dense moved directly before him. In the left eye, at the same time, pearly spectra appeared, which gradually expanded into a spider-like body, seen at A (Fig. 14). This followed the motion of the eyeball from right to left or upwards and downwards; but the densest part was always more in the centre of the pupil than shown at A. After a few weeks of medical treatment and perfect rest, some improvement began to manifest itself. While he was lying on the couch one day, a dark-looking fluid, "as black as ink", appeared to flow from the ovoid body situated at the top of the diagram s. On another occasion, it was all transformed into the jagged figure at $\mathrm{c}$; and on stooping down and rather suddenly raising the head, it expanded into the curious looking body seen at $\mathbf{D}$. The space on each side was always a perfect blank; doubtless insensible portions of the retina. The most marked improvement occurred while out walking in a clear bright atmosphere, when nearly all the spectra somewhat suddenly vanished from before both eyes. The right eye had several relapses, but sight slowly returned; and when last seen, he could read without producing fatigue either Greek or German; he could also see distant objects quite clearly, when he used glasses which neutralised the myopia. It was expected by his medical attendant that the retina had become detached in the right eye; but upon making an examination with the ophthalmoscope, an advanced staphyloma posticum, $\uparrow$ a few

* "Peculiar phennmena may be produced by these groups of scotomata: thus I have seen cases in which very small print was more easily and more quickly read than a larger one, because of the latter a whole word was never seen at once, and letters sill larger were only party visible. 'The glimmering usully comploined of were only party visible. The glimmering ustally complained of 1 entirely due to the fact, that in slight movements of the eye the
letters form their images alternately on sensitive and insensitive parts, and thus each time come and disappear, sometimes with change of form, according to irregular displacement of the percipient elements." (Donders, op. cit.)

+ "Ophthalmoscopic investigation has shown that almost withou exception, even in moderate degrees of myopia, chauges, especially in the choroid, are to be observed; and it has been further found, that these changes are the expression of atrophy of the choroid, which, combined with atrophy of the sclerotic, is, as well as the latter, dependent on a distention of the posterior part of the eyehall. MIycpia and staphuloma posticum bave become nearly synonymous." (Uonders, op. cit., page 354.) small, dark, scattered bodies in the vitreous humour, and an anæmic retina, were the changes discovered; so that to insensibility of the retina must we ascribe most of the distressing symptoms in this case.

Sir David Brewster, whose attention was early directed to these phantoms, in consequence (as he tells us) of the annoyance he experienced in his own eyes, observes of them "that, as they exist in all eyes, whether young or old, they are neither the result of disease, nor do they indicate its approach." This opinion Brewster afterwards qualified; and stated that, although some of the phenomena of musca may be seen by persons of all ages, and with the best eyes, "those which are more peculiarly entitled to the name, are exceedingly common beyond the middle period of life."

On the other hand, we know that opinions are still a good deal divided on this question. The older writers, as Pitcairn, Boerhaave, Plenck, and others, regarded all spectra with alarm; and believed that they were always indicative of retinal disease. De la Hire said "that only presbyopics were troubled with muscæ". The Royal Academicians of Paris added, that myopes are not more exempt from them than presbyopes. Wardrop says, "Short-sighted people are least liable to this affection". Donders has satisfied himself, both entoptically and microscopically, that, as age advances, muscæ float about in all eyes; but " that myopes are more troubled with them than others."* Dr. Mackenzie writes of them, "Certain it is, that the pearly spectrum is recognisable by all eyes, when sought for through a pinhole or through the eye-glass of a compound microscope. Yet eyes of normal conformation are seldom subject to muscæ (myodesopia). On the contrary, when a person complains much, he will always be found either myopic or presbyopic, or perhaps one eye will be myopic and the other presbyopic." This passage has been somewhat unfairly assailed; and, therefore, Dr. Mackenzic has endeavoured to make his meaning clearer: stating that (so far as he has been able to judge from a most extended practice) " eyes of normal conformation are seldom subject to muscæ; and, when a person complains much of muscæ, we always find him either myopic or presbyopic."

I have met with several persons, whose eyes were emmetropic, and possessed unimpaired power of accommodation, who nevertheless complained of myodesopia; and, therefore, I can go thus far with Sir David Brewster and others, in saying that sufferers from "muscæ" are not necessarily myopes or presbyopes. Dr. Mackenzie, however, complains that it should be said that he alleged as a reason why only myopic or presbyopic eyes are subject to muscæ, that "an accurate refocalisation of light issuing from external points upon the retina prevents their being projected thereon." But he denies that he ever said this ; and gives the following as his opinion, that "the interception of the rays proceeding from external objects by filaments in front of the retina, or

* "In the circles of diffusion of smaller surfaces of light, they exhibit themselves with extraordinary distinctness; and in general, the inore diffilse uniform aspe

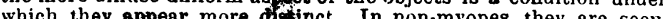
which they are seen aniformly illuminated surfaces, while no a diminution of this symptom from the a diminution of this symptom from the use of concave glasses, which remove the uniform diffuse appearance of objects. But often the complaints continue, especially when the patients are uneasy about the symptom, and have once accustomed themselves to attend to it. I have seen instances in which anxiety about muscr volitantes amounted to true mouomania. against which all reasoning and the most direct demonstrations were in rain. This is especially the case when morbid changes in the vitreous humour have supervened. We must arimit the existeuce of morbid changes as soon as we cau with the ophthalmoscope perceive turbidities in the vitreous humour. And to these real (Donders, op. cit., page 894.) 
even the formation of magnified shadows by diffraction, produces comparatively little effect when the remainder of those rays are brought accurately to focal points upon that membrane. As I think, almost every one will perceive I mean ' comparatively little effect' upon the percipient organ."

This is certainly a very different statement from that contained in the quotation complained of; the one being the positive assertion of a supposed fact, involving an absurdity in reasoning upon optical effects; the other a modified statement which does not imply absolute contradictior of a well known fact. For the assertion that "comparatively little effect" is produced, does not amount to a denial that any effect is produced; on the contrary, it is an admission that some effect is produced, and that is all that is needed to render Dr. Mackenzie's assertion on this point compatible with the experience of other observers. Accidental circumstances, such as overwork of eyes or brain, as I have already shown, doubtless renders the perception of all muscæ greater and more annoying; and the indistinctness of images of external images in the case of either myopic or presbyopic eyes must, to a certainty, favour these distressing appearances and render them more perceptible.

One other illustration fully establishes the fact that, by neutralising the myopia, a marked diminution of the myodesopia takes place; the muscæ volitantes are (as Dr. Mackenzie says), "to a certain extent, extinguished in perfect vision", i.e., by a brilliant light, or by glasses which neutralise the myopia. Fig. 15 represents the field of vision of the left eye

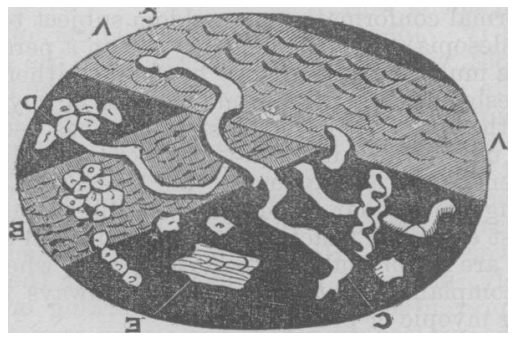

Fig. 15.

on a dark winter's day when the eye was directed towards a lightish part of the sky. The band $\mathrm{A} A$ is a floating portion of lacrymal fluid passing slowly over the cornea. $\mathbf{B}$ is a similar band, with pearly globules. From $\mathrm{C}$ to $\mathrm{c}$ are images of fibres in the vitreous humour. Near $\mathrm{D}$ is a group of pearly beads, very indistinctly seen, when compared with those on the band $B$. Near $E$ is seen an anæmic portion of retina.

Fig. 16 represents the field of vision of the left eye precisely under the same conditions of light as the

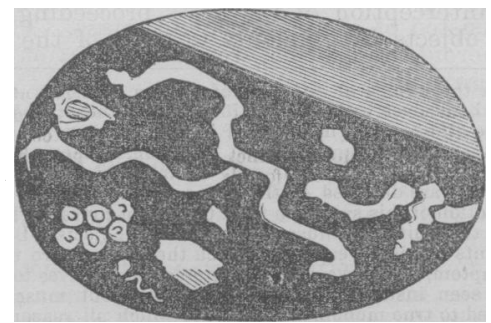

Fig. 16.

former fig. 15; but furnished with an appropriate glass to correct the myopia. In this diagram, it will be observed that one of the floating bands of fluid is very faint; the other has quite disappeared from view. The fibres in the vitreous humour and the anæmic portion of retina are still visible; but several of the loose beads are no longer seen, and others become much fainter.

Fig. 17 represents the field once more of the left eye when directed toward the sky illuminated by a

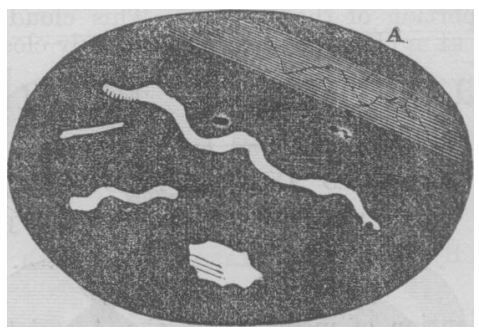

Fig. 1\%.

brilliant sunlight. In this very bright light, although the sight was quite unprotected, the images became fewer, and almost wholly confined to the anæmic portion of the retina, the deeper fibres in the vitreous humour, and to a very slight and fiagmentary portion of the lacrymal fluid, much less distinctly seen than delineated at $\mathrm{A}$.

Fig. 18 again represents the field of vision assisted by a concave glass, and directed to a clear sky under

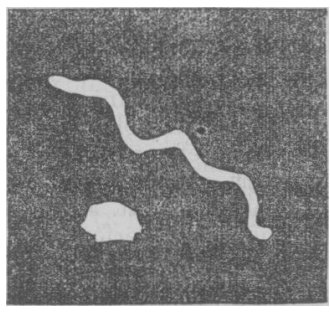

Fig. 18.

the same conditions as the former figure; namely, a brilliant sunlight.

So much for a good clear light and appropriate spectacle-glasses on the visibility of some musce But I have found musce liable to be affected to a much greater extent by internal than by external circumstances; by only a slight derangement of health during a period of fatigue or overwork of the brain and eyes. As an instance of this, I give the field of vision of this gentleman after a period of prolonged anxiety and study.

Fig. 19 represents the left eye. The "veils" are very numerous, and merge so much into each other,

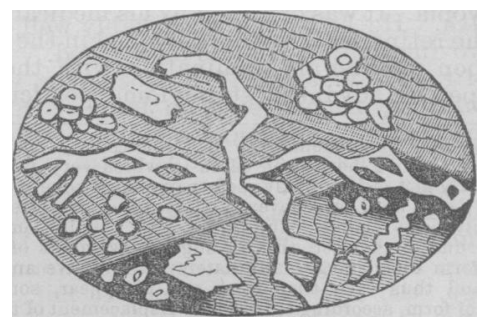

Fig. 19.

that it is difficult to say where one breaks off and the other commences. The fibres in the vitreous humour are numerous and very distinctly seen; the anæmic portions of the retina are two in number; the groups of beads larger and more numerous; in short, the 
whole field of vision is peopled with entoptical spectra. In this condition, no glasses of any form appeared to diminish the number of spectra, lessen the inconvenience experienced, afford rest, or assist the sight in the least degree more; but when, after a period of rest and sleep, glasses were again tried, then a considerable diminution of the visio phantasmatum invariably resulted.

\section{Cramsactions of âdramethes.}

\author{
BATH AND BRISTOL BRANCH. \\ ENUCLEATION OF THE EYE. \\ By Frederich Mason, Esq., Bath. \\ [Read December 1st, 1864.]
}

The attention of members of the Association was directed to this subject by a leading article in the Journal of Norember 5th ; and, as the question may arise as to the proper treatment to be adopted in a certain class of cases, I have considered the following may not be uninteresting, and may lead to useful discussion.

Judging from the records of the Bath Eye Infirmary, the operation of enucleation of the eye has not been a frequent one; for, on examining the casebooks for the last fourteen years, I can only find an account of two eyes removed for disease arising from traumatic causes, in addition to two which have occurred during the present year.

I have not included those removed on account of malignant disease; but have confined myself to those cases where one eye has begun to suffer-the other having been lost by some wound or injury. The first two are from the case-book of the late Mr. Boult.

CASE r. George Best, aged 37, a labourer, was admitted an in-patient of the Infirmary on September 6 th, 1859, suffering from low traumatic ophthalmitis. $\mathrm{He}$ was dismissed on October 1st much better. On October 25th he was readmitted. As soon as he had been out a few days, all the symptoms returned, and it was determined to remove the eye to save the other, which was beginning to suffer. The eye was removed by Mr. Boult. No difficulty occurred, and he was discharged with the right eye good, on November 7 th.

CASE Ir. Samuel I., aged 37, a labourer, was admitted on January 23rd, 1860, suffering from traumatic loss of right eye. $\mathrm{He}$ lost his right eye by a blow from a stone two years previously, and the same globe had always been painful and irritable since. The left eye began to suffer, and it seemed necessary that the injured globe should be removed.

Jan. 28th. Mr. Boult extirpated the right eye.

Feb. 4.th. He had done remarkably well, the left eye improving daily. He was discharged.

CASE III. J. W., aged 47, a shoemaker, was sent to the Infirmary from Frome, on January 28th, 1864. He stated that, five years and a half ago, when chopping wood, a splinter entered the left eye, and destroyed vision. This eye is now shrunk and hard, and the cornea is altogether wanting. In the winter of 1862 and 1863, he found the sight in the right eye failing, but recovered during the summer. Six weeks ago, the sight again began to fail, and became worse so rapidly, that he had no useful or distinct vision, and was unable to distinguish the largest type.

The eye (the right) had a very dull hazy look. On examining it with the ophthalmoscope, the light did not penetrate to the fundus, and the reflection from the choroid was of a dark, reddish-black colour. Be- lieving the remains of the left eye to be the source of all the mischief, I did not hesitate to recommend him to submit to its removal; and, accordingly, on the $30 \mathrm{th}$, he was placed under the influence of chloroform, and the eye was extirpated. Immediately after the operation, severe vomiting came on, but ceased soon after he was in bed.

Jan. 31st. He had passed a good night, and was doing well.

Feb. 3rd. The sight of the right eye was already very much improved, and he could read distinctly without the aid of a glass (he had previously worn spectacles) a text of scripture in large type fixed against the wall of the room.

Feb. 9th. He was discharged.

A fortnight after he left the Infirmary, he wrote to the matron, and said he had that day worked for four hours, repairing shoes; and he had no doubt that he should, in another week, be able to do a full day's (twelve hours) work.

Before bringing this case before you, I was desirous of knowing this man's condition at the present time. I therefore requested the matron to write to him. The following is an extract from his letter, dated November 21st, 1864.

"I did not try to work till a fortnight after I came home; the first day I could work but one hour; the next day about two and a half hours; the next day four hours; and within a fortnight, I could work twelve hours a day; but now I could work twenty hours a day if I wished to. Where there is good light, I can see to read the newspaper without glasses for a short time, but I generally use them for reading, but not in work.",

CASE IV. John C., aged 37, a labourer, on April 23rd, 1864, was sent from Malmesbury to the Infirmary. He stated that, twenty years ago, the left eye was wounded with a piece of glass, and the sight was lost-probably from traumatic cataract. This eye remained quiet and without pain until two years ago, when he received a blow on the temple. The eye now became inflamed, and there had been constant pain ever since. He was on admission suffering intensely, nat only in the eye but over the brow, which prevented him from either working or sleeping. The eye was congested, the cornea semi-opaque, with a large central portion perfectly so, and yellowish in colour, with commencing sloughing. Against this an opaque lens appeared to be resting. The right eye was weak, and constantly suffused with tears; and the tension was much greater than natural.

On April 24th he was placed under the influence of chloroform, and I removed the left eye. On dissection, the anterior chamber was found to be obliterated in consequence of the iris being firmly adherent throughout to the cornea, and to the capsule of the lens. The pupil was somewhat dilated, with the lens pressing forward through the opening. The lens consisted of a soft flocculent mass. 'The sclerotic, choroid, and retina, were all agglutinated and undistinguishable.

April 25th. Shortly after the operation all pain ceased, and he slept well through the night.

April 28th. He had had no return of pain.

May 5th. He had done well. The right eye continued to feel weak, if exposed to a bright light. He was discharged.

Since this man returned home, I have not seen or heard from him, excepting indirectly through other patients that he was able to keep to his work.

In neither of these cases was there any hæmorrhage or constitutional disturbance after the operation ; the after-treatment consisted in simply keeping a piece of lint wet with cold water over the eyelids, 